Mitchell Raper (Orcid ID: 0000-0002-5435-8505)

Seeing into the future: The role of future-oriented coping and daily stress appraisal in relation to a future stressor

Mitchell Raper* and Paula Brough

School of Applied Psychology, Griffith University, Australia

*Correspondence concerning this article should be addressed to: Mitchell Raper, School of Applied Psychology, Griffith University, Mount Gravatt Campus, Queensland 4122,

Australia. Email: mitchell.raper@ griffithuni.edu.au; Telephone +6137353302

This article has been accepted for publication and undergone full peer review but has not been through the copyediting, typesetting, pagination and proofreading process, which may lead to differences between this version and the Version of Record. Please cite this article as doi: 10.1002/smi.2984.

This article is protected by copyright. All rights reserved. 
Acknowledgements: The authors acknowledge the assistance of Dr. Amanda Biggs with part of the design and measurements used in this research.

Conflicts of Interest: The authors declare no conflicts of interest regarding this project.

Data Availability Statement: Data available upon request. Please contact the corresponding author.

Funding: No funding was received for the study.

Informed Consent: Informed consent was obtained from all participants included in the study.

This article is protected by copyright. All rights reserved. 


\begin{abstract}
Recent research has identified the value of distinguishing between employee's appraisals of their work-based challenge, hindrance, and threat job demands, and of how employee's futureoriented coping is associated with key occupational outcomes. The current study extends this research by assessing the extent to which employee's proactive and preventive coping techniques each directly and indirectly predicted challenge, hindrance, and threat appraisals. Utilising a daily diary design, 89 undergraduate students completed five daily surveys focused on a common future stressor. Results suggested daily appraisals do not change as much as expected, with only challenge appraisals reducing across the five-day period. However, both proactive and preventive coping moderated daily stress appraisals, such that when proactive coping was high, challenge appraisals increased, and hindrance appraisals decreased. Similarly, preventive coping appeared to reduce both hindrance and threat appraisals. Theoretical and practical implications of the multi-level and dynamic nature of appraisals and future-oriented coping are discussed.

Keywords: challenge appraisal, hindrance appraisal, threat appraisal, proactive coping, preventive coping
\end{abstract}

This article is protected by copyright. All rights reserved. 


\section{Seeing into the future: The role of future-oriented coping and daily stress appraisal in relation to a future stressor}

The stress and coping process is dynamic, with recent research focusing on the daily fluctuations of the stressor-strain relationship (Pindek et al., 2019). Although the transactional model of stress and coping defined stress as an interactive process between an individual and their environment (Lazarus \& Folkman, 1984), research largely overlooks individual cognitive appraisals (Searle \& Auton, 2015), especially when anticipating a future stressful event (e.g., Skinner \& Brewer, 2002). Evidence is clear that persistent exposure to stress is associated with negative health and work outcomes, including depression, anxiety, burnout, absenteeism, and increased negative affect (Brough et al., 2018). However, many assumptions are still taken for granted when conceptualising the stress and coping process. For example, the a priori categorisation of job demands into challenges or hindrances assumes that the primary appraisal of these demands across individuals is equal (Webster et al., 2011). Second, future-oriented coping posits that individuals can cope with future stressors (Schwarzer, 2000). However, the majority of coping research continues to focus on how individuals cope in the presence of a past or present stressor, rather than an anticipated future event (Drummond \& Brough, 2016b). The current research advances these scholarly discussions by investigating how future-oriented coping (both proactive and preventive coping) impacts the daily stress appraisals of an anticipated future stressor. Specifically, how proactive and preventive coping moderate the process of daily challenge, hindrance, and threat appraisals in anticipation of a common stressor.

\section{Challenge, Hindrance, and Threat Appraisals}

According to the transactional stress model, individuals appraise an event as stressful if they believe they do not have the capacity to overcome the stressor, resulting in the individual 
appraising the stressor as a harm/loss that has already occurred, an anticipated threat of future harm or loss, or a challenge for potential gain, mastery, and growth (Lazarus \& Folkman, 1984). Cavanaugh et al. (2000) utilised these appraisal definitions to categorise common job demands into either challenges or hindrances. While this challenge-hindrance framework has been successful in differentiating the effects of job stressors on both positive (e.g., performance and engagement) and negative (e.g., burnout and strain) organisational outcomes (Crawford et al., 2010), recent research has argued the distinction between challenge and hindrance demands is not so clear (Searle \& Auton, 2015). For example, the transactional stress model proposed individuals appraise stressors as challenging, threatening, or a mixture of both (Lazarus \& Folkman, 1984). Whereas, the challenge-hindrance framework assumes specific job characteristics (e.g., job responsibility and time pressure) are challenges, while other job characteristics (e.g., emotional demands, role conflict, and role ambiguity) are hindrances (Searle \& Auton, 2015; Webster et al., 2011). However, evidence also indicates that learning demands, workload, time pressure, role ambiguity, and role conflict can simultaneously be appraised as both a challenge and a hindrance (Searle \& Auton, 2015), thereby, supporting the inclusion of cognitive appraisals within the stress process and blurring the challenge-hindrance conceptual distinction.

A second limitation of the challenge-hindrance framework is that threat appraisals are not specifically accounted for, thereby ignoring this proposition of the transactional stress model (Tuckey et al., 2015). Some authors have suggested hindrance and threat appraisals are interchangeable. For example, job hindrances have been described as being "threatening to the self' (Crawford et al., 2010, p. 845). However, Tuckey and colleagues (2015) argued for construct distinction: hindrance appraisals are primarily focused around goal and learning 
obstruction, and threat appraisals are focused more on the self. This is evidenced by threat appraisals being associated with increased anxiety, while hindrance appraisals are associated with anger and frustration (Tuckey et al., 2015). Scarce research has examined the effects of these three types of appraisal, and especially how they each influence the stress and coping process via future-oriented coping.

\section{Future-Oriented Coping}

Coping taxonomies described in the literature are predominately reactive in nature, failing to account for anticipated future events or stressors (Aspinwall \& Taylor, 1997). As such, Aspinwall and Taylor (1997) argued coping could occur due to anticipating future threats, rather than coping in the presence of a stressor. While proactive coping is defined as the efforts one puts in to reduce the impact of future threats as per Aspinwall and Taylor's (1997) definition, Schwarzer (2000) instead described a four-factor proactive coping theory consisting of: reactive, anticipatory, proactive, and preventive coping. Reactive coping describes efforts to manage the harm or loss associated with a present or past stressor (Schwarzer \& Taubert, 2002). Anticipatory coping focuses on a known stressful event occurring in the near future, such as an examination or presentation (Schwarzer \& Taubert, 2002). Proactive coping concerns the gathering of resources to enrich the potential to grow and learn. Finally, preventive coping describes gathering resources to prepare for specific threats in the future (Schwarzer \& Taubert, 2002). While both proactive and preventive coping are future-oriented, there are distinctions between these two coping styles (Biggs et al., 2017; Drummond \& Brough, 2016b; Gan et al., 2007; Schwarzer \& Taubert, 2002). Despite Schwarzer's (2000) conceptualisation of future-oriented coping, there is considerable overlap between Schwarzer's (2000) definition of preventive coping 
and Aspinwall and Taylor's (1997) definition of proactive coping. First, Aspinwall and Taylor's (1997) definition of proactive coping only accounts for future threats, harms, or losses without considering preceding challenge appraisals. Second, according to Schwarzer and Taubert (2002), proactive coping focuses on growth and development, and is specifically associated with challenge appraisals and goal management, such as attending a workshop or programs to gain relevant skills and knowledge to complete a task. Preventive coping is associated with the reduction of negative outcomes of future threats and as such, focuses more specifically on risk management (Schwarzer \& Taubert, 2002). This definition of preventive coping by Schwarzer and Taubert (2002) is in line with Aspinwall and Taylor's (1997) definition of proactive coping. As such, Schwarzer's (2000) definitions of proactive and preventive coping are more consistent with the transactional model due to being more inclusive of both challenge and threat appraisals. Furthermore, research on promotion pride and prevention pride have indicated similarities between proactive and preventive coping respectively (Higgins et al., 2001). Such that those with promotion pride tend to have more of an achievement and approach orientation to attain goals, whereas individuals with prevention pride tend to have more of an avoidance orientation in order to avoid potential mismatches with desired end states (Higgins et al., 2001).

Proactive and preventive coping have each been investigated within both work and nonwork domains (e.g., Drummond \& Brough, 2016b; Gan et al., 2014; Hu \& Gan, 2011; Sohl \& Moyer, 2009) and have each demonstrated positive relationships with wellbeing (Drummond \& Brough, 2016a; Greenglass \& Fiksenbaum, 2009), and reduced burnout (Angelo \& Chambel, 2014). A deficiency in the research to date, is the dominance of assessing future-oriented coping as mediators within the stress process. Relatively few studies have investigated the moderating 
role of future-oriented coping; suggesting that future-oriented coping could be described as a personal resource (Searle \& Lee, 2015).

\section{The Moderating Role of Future-Oriented Coping}

Due to the resource gathering nature of future-oriented coping, it has been suggested these coping strategies may buffer the relationships between stressors and wellbeing (Niessen et al., 2018; Searle \& Lee, 2015). Future-oriented coping allows individuals to proactively prepare for events by achieving realistic goals or developing required skills, or by gathering resources to help overcome identified threats, thus reducing the potential for negative outcomes (Schwarzer $\&$ Taubert, 2002). Some researchers have, therefore, conceptualised future-oriented coping as a personal resource within a job demands-resources perspective (e.g., Angelo \& Chambel, 2014; Searle \& Lee, 2015). Researchers have also suggested that future-oriented coping can limit resource loss and/or help gain resources when anticipating future events, thus creating resource caravans (e.g., Niessen et al., 2018).

Research investigating the moderating effects of proactive and preventive coping generally supports these theoretical suggestions. For example, Stiglbauer and Batinic (2015) found that when employees were faced with high job insecurity, proactive copers who were highly involved in their job were able to reduce strain by increasing their levels of available resources; see also (Niessen et al., 2018). Studies examining multi-level interactions of coping and appraisals are scarce. Espedido et al. (2019) for example, investigated the moderation of both individual-level and team-level problem prevention (proactive coping) on the relationship between stress appraisals and problem-solving demands. They found that team problem prevention moderated the relationship between individual challenge appraisal and problemsolving demands, such that teams with higher problem prevention had increased challenge 
appraisals when problem-solving demands were high (Espedido et al., 2019). Recent reviews of the challenge-hindrance framework have called for further investigations of the moderation between proactive and other future-oriented coping styles and stressors (O'Brien \& Beehr, 2019), indicating the need to further understand the role of hindrance appraisals with future-oriented coping.

\section{The Current Research}

The current research extends our understanding of stress and coping in two ways. First, how stress appraisals can change as a common future stressor approaches, in this case, a laboratory report. Second, to understand the moderating effect of proactive and preventive coping on daily stress appraisals. The transactional stress model posits that the same stressor can be appraised differently by individuals and can even be appraised simultaneously as a challenge, hindrance, or threat (Lazarus \& Folkman, 1984; Searle \& Auton, 2015; Webster et al., 2011). Similarly, the dynamic nature of stress appraisals indicates their (potential) to change each day (Ohly \& Fritz, 2010), thus the current study utilised a daily diary research design to capture the within-person variability of stress appraisals. Furthermore, as stressors approach, individuals may appraise them more strongly as the stressor becomes more relevant to their wellbeing (Lazarus \& Folkman, 1984; Skinner \& Brewer, 2002).

Firstly, in regard to challenge appraisals, as the stressor approaches, there should be increased perceptions of time pressure and workload, which have been previously classified as challenge stressors (Crawford et al., 2010) and have been appraised as challenging (e.g., Searle \& Auton, 2015; Webster et al., 2011). As such, stronger challenge appraisals should be elicited due to goal progress (Espedido \& Searle, 2018). As individuals complete their goals, they are able to recognise the potential for learning, development, and 
mastery, which should elicit higher challenge appraisals as the stressor approaches (Espedido \& Searle, 2018; Skinner \& Brewer, 2002). Second, as individuals work towards overcoming a stressor, there is the potential for goal obstruction, particularly if faced with difficult goals (Espedido \& Searle, 2018). Goal obstruction is known to increase feelings of frustration, which is consistent with hindrance appraisal (Lazarus, 1991; Tuckey et al., 2015). Perceptions of time pressure and workload may also increase if individuals are unable to overcome obstructions quickly, which have been associated with hindrance appraisal (Searle \& Auton, 2015; Tuckey et al., 2015; Webster et al., 2011). Finally, as a stressor becomes more salient to individuals, the expectation to meet tight deadlines can induce feelings of potential harm or loss due to the possibility of an undesired result like failure which can increase perceptions of threat (Espedido \& Searle, 2018; Skinner \& Brewer, 2002). Therefore, it is expected that as the common future stressor approaches, stress appraisals over several days will also increase.

Hypothesis 1: There will be positive relationships between days and stress appraisals. That is, the slopes between days and challenge appraisals (H1a), hindrance appraisals (H1b), and threat appraisals (H1c) will be positive.

The key distinction between proactive and preventive coping are their associated cognitive appraisals (Schwarzer \& Taubert, 2002). The goal management focus of proactive coping is associated with challenge appraisals, so it is expected that proactive copers should have increased challenge appraisals as the future stressor approaches. Alternatively, preventive coping is associated with threat appraisals due to efforts taken to reduce the negative outcomes of anticipated threats. Thus, preventive copers should have reduced threat appraisals as the future stressor approaches. 
Hypothesis 2a: Proactive coping will be positively associated with challenge appraisal. Hypothesis 2b: Proactive coping will moderate the relationship between days and challenge appraisal, such that individuals with high levels of proactive coping will have increased challenge appraisals across days.

Hypothesis $3 a$ : Preventive coping will be positively associated with threat appraisal. Hypothesis $3 b$ : Preventive coping will moderate the relationship between days and threat appraisal, such that individuals with high levels of preventive coping will have reduced threat appraisals across days.

Proactive and preventive coping may also moderate the relationship between hindrance appraisals across days. Due to the ability of proactive copers to accumulate resources to assist with their goals and achievements (Schwarzer \& Taubert, 2002), proactive coping should be negatively associated with hindrance appraisals, and proactive copers should have reduced hindrance appraisals as the future stressor approaches. Alternatively, preventive coping should be positively associated with hindrance appraisals, thus preventive copers should have reduced hindrance appraisals as the future stressor approaches.

Hypothesis 4a: Proactive coping will be negatively associated with hindrance appraisal. Hypothesis 4b: Proactive coping will moderate the relationship between days and hindrance appraisal, such that individuals with high levels of proactive coping will have reduced hindrance appraisals across days.

Hypothesis 5a: Preventive coping will be positively associated with hindrance appraisal. Hypothesis 5b: Preventive coping will moderate the relationship between days and hindrance appraisal, such that individuals with high levels of preventive coping will have reduced hindrance appraisals across days.

This article is protected by copyright. All rights reserved. 


\section{Method}

\section{Participants and Procedure}

A sample of undergraduate students enrolled in a university psychology course were recruited for this study. Of the 104 participants, five (4.8\%) completed one daily survey, 10 (9.6\%) completed two daily surveys, 13 (12.5\%) completed three daily surveys, $22(21.2 \%)$ completed four daily surveys, and 54 (51.9\%) completed all five daily surveys. The final sample consisted of $N=89$ students who completed at least three of the five daily surveys. The participants' demographics were consistent with the course demographics, with most respondents being female $(n=58 ; 65 \%)$ and with an age range of $18-51$ years $(M=22.59, S D$ =7.69). Following institutional review board approval (GU ref: 2017/279), participants were recruited through an online registration process via their university website, which described the purpose and details of the study. The registration survey included the participant information sheet, which outlined the procedure of the daily diary study, so participants knew what they were required to do before consenting to participate. Next, participants were asked whether they consented to voluntarily participate in the study with the knowledge that they can withdraw from the study at any time without penalty. Once participants consented to participate, they provided their email address and mobile phone number in order to receive their daily surveys. Five days prior to a major assignment submission, participants were administered their first daily survey via their mobile phone, this was repeated across the subsequent four days until the day before assignment submission, resulting in a total of five daily surveys. All participants upon completion or voluntary withdrawal received research credit for their course as well as the option to receive a personal report of their responses compared to the de-identified sample. 


\section{Measures}

Each measure item was adapted to the daily level to adequately capture daily

fluctuations. Utilising the procedure described by Geldhof et al. (2014), internal consistencies were calculated separately for both within $\left(\alpha_{\mathrm{w}}\right)$ and between $\left(\alpha_{\mathrm{b}}\right)$ persons.

\section{Days. Days were measured as days 1-5 of participation.}

Challenge and hindrance appraisals. Challenge and hindrance appraisals were measured with Searle and Auton's (2015) scale. The appraisal scales were framed around the upcoming assignment (a laboratory report; "Please think about the upcoming lab report. Please now assess how this task is likely to affect you"). The scale consists of eight items measuring challenge appraisal (four items) and hindrance appraisal (four items). Example items include “Today, it will show me I can do well" (challenge appraisal; $\left.\alpha_{w}=.65 ; \alpha_{b}=.94\right)$ and "Today, it will restrict my capabilities" (hindrance appraisal; $\alpha_{\mathrm{w}}=.63 ; \alpha_{\mathrm{b}}=.95$ ). Responses were recorded on a 5-point Likert-scale ranging from 1 (strongly disagree) to 5 (strongly agree).

Threat appraisals. Threat appraisals was measured with Feldman and colleagues' (2004) three-item measure. Items include "Today, I feel that this task may be a negative experience for me" $\left(\alpha_{\mathrm{w}}=.70 ; \alpha_{\mathrm{b}}=.98\right)$. Responses were recorded on a 5-point Likert-scale ranging from 1 (strongly disagree) to 5 (strongly agree).

Proactive and preventive coping. Drummond and Brough's (2016b) revised Proactive and Preventive Coping subscales of the PCI (Greenglass et al., 1999) was employed to measure future-oriented coping. The coping items were prefixed with the following statement "Please indicate how true each of these statements are depending on how you feel about the upcoming lab report". The proactive coping subscale consists of eight items, including "Today, I like challenges and beating the odds" $\left(\alpha_{\mathrm{w}}=.81 ; \alpha_{\mathrm{b}}=.97\right)$. The preventive coping subscale consists of 
five items, including "Today, I prepare for adverse events" and "Today, I think ahead to avoid dangerous situations" $\left(\alpha_{\mathrm{w}}=.74 ; \alpha_{\mathrm{b}}=.98\right)$. Responses were recorded on a 4-point Likert-scale from 1 (not at all true) to 4 (completely true).

\section{Statistical Analysis}

Statistical analyses were conducted in Mplus Version 8 (Muthén \& Muthén, 1998-2017) using multilevel confirmatory factor analysis (MCFA) and a random effects model. MCFA and random effects models can be used in hierarchical datasets with daily measurements (Level 1; the daily level) nested within persons (Level 2; the person level). Three sets of MCFAs were conducted on the stressor appraisal and future-oriented coping variables to test the predicted factor structure of all items at both levels of analysis. First, a MCFA was conducted on the challenge, hindrance, and threat appraisal items to test the differentiation between hindrance and threat appraisals. Second, a MCFA was conducted with the proactive and preventive coping items to test the divergence of these two constructs. Finally, all appraisal and coping items were entered into a final measurement model to test the relationships between all latent constructs. A random effects model was then employed to test the multi-level moderation of proactive and preventive coping on the random slopes between days and stress appraisals.

\section{Results}

\section{Development of Measurement Models}

Challenge, hindrance, and threat appraisal measurement model. All 11 appraisal items were entered into a MCFA with three latent factors representing the three appraisals at each level of analysis. All items had intraclass correlations (ICC) between .50 and .69, indicating the suitability of multilevel analyses due to sufficient proportions of variances at both the between-persons and within-persons levels. One hindrance appraisal item returned a low 
standardised within-person factor loading of .23 and the hindrance appraisal latent factor did not account for significant variance of this item at the within level $\left(R^{2}=.05\right)$. In addition, one challenge appraisal and one threat appraisal item resulted in negative error variances at the between level. Consequently, the hindrance item was removed from the model and the challenge and threat appraisal item's error variances were constrained to zero at the between level. This three factor MCFA produced acceptable fit statistics $\chi^{2}(66)=102.39, \chi^{2} / d f=1.55, p<.01 ; \mathrm{CFI}=$ $.97, \mathrm{TLI}=.95, \mathrm{RMSEA}=.04, \mathrm{SRMR}=.05($ within $) / .06$ (between). To test the differentiation between hindrance and threat appraisals, a two factor MCFA was conducted with all hindrance and threat appraisals loading onto the same latent variable at both levels. This produced a significantly worse fit to the data $\chi^{2}(70)=307.25, \chi^{2} / d f=4.39, p<.001 ; \mathrm{CFI}=.77, \mathrm{TLI}=.71$, $\mathrm{RMSEA}=.09, \mathrm{SRMR}=.07($ within $) / .12($ between $), \Delta \chi^{2}(4)=204.86, p<.001$.

Proactive and preventive coping measurement model. The 13 coping items were entered into a MCFA with two latent factors representing the two future-oriented coping factors at each level of analysis. All items had ICCs between .34 and .44. The two-factor model produced an acceptable fit to the data: $\chi^{2}(128)=254.31, \chi^{2} / d f=1.99, p<.001 ; \mathrm{CFI}=.93$, TLI $=$ .92, RMSEA $=.05$, SRMR $=.05$ (within) $/ .06$ (between). To test the differentiation between proactive and preventive coping, a one factor MCFA was conducted with all coping items loading onto the same latent variable at both levels. This produced a significantly worse fit to the data: $\chi^{2}(130)=579.87, \chi^{2} / d f=4.46, p<.001 ; \mathrm{CFI}=.76, \mathrm{TLI}=.71, \mathrm{RMSEA}=.09, \mathrm{SRMR}=$ .07 (within) $/ .10$ (between), $\Delta \chi^{2}(2)=325.56, p<.001$.

Full measurement model. In the final step, both the appraisal and coping models were combined into a full measurement model. Due to having a low sample size at the between level $(N=89)$, a two-step approach (Anderson \& Gerbing, 1988) was employed to allow the model to 
converge. The factor loadings and residual variances of the appraisal and coping items were constrained based on their respective models. The resulting five-factor model produced an acceptable fit to the data: $\chi^{2}(522)=616.46, \chi^{2} / d f=1.18, p<.01 ;$ CFI $=.97$, TLI $=.97$, RMSEA $=.02, \mathrm{SRMR}=.05$ (within) $/ .07$ (between). For the random effects models, observed variables (mean scale scores) were employed rather than latent variables, to reduce the complexity of the parameters being estimated due to the small between-person sample.

\section{Scale Descriptives}

The ICCs ranged between .56 and .83, justifying multilevel analyses (Table 1). As expected, challenge appraisals were negatively related to hindrance and threat appraisals, while hindrance and threat appraisals were positively related to each other. Proactive and preventive coping produced high associations with each other at both levels of analyses. Proactive coping was positively correlated to challenge appraisals and negatively correlated with hindrance and threat appraisals. However, preventive coping was negatively related only to hindrance appraisals at the between-person level.

\section{INSERT TABLE ONE ABOUT HERE}

\section{The Effects of Days on Stress Appraisals}

The correlations between days and challenge appraisals within-persons were negatively related, and no significant relationships occurred between days and hindrance and threat appraisals. Table 2 summarises the multilevel estimates and reports the mean value of the random slope for the relationship between days and challenge appraisal within-persons was negative, while the mean value for the random slope between days and hindrance and threat appraisals were not significant. Hypotheses 1a, 1b, and 1c were therefore, not supported. INSERT TABLE TWO ABOUT HERE 


\section{The Moderating Role of Future-Oriented Coping on Daily Stress Appraisal}

In the four random effects models, the main effect of Level 2 proactive and preventive coping $\left(\gamma_{01}\right)$ on stress appraisals was included to assess the direct relationship between these constructs. To assess for multi-level moderation, Level 2 variables were employed to predict the random slope of the explanatory variable on the outcome variable (Preacher et al., 2006).

Proactive and preventive coping predicted the random slope between days and stress appraisals $\left(\gamma_{11}\right)$. If significant moderation occurred, simple slopes analyses were also conducted.

The main and moderating effects of proactive coping on challenge appraisal. The direct effects of proactive coping on challenge appraisal was positive but not significant, thus Hypothesis 2a was not supported (Table 3). The multi-level moderation effect of proactive coping on the relationship between days and challenge appraisal was significant $\left(\gamma_{11}=0.09, p<\right.$ $.05)$. Figure 1 depicts the interaction between days and challenge appraisal for low (-1 SD) and high (+1 SD) levels of proactive coping. At low levels of proactive coping, the simple slope was significant $(-.11, p<.01)$, while at high levels of proactive coping the simple slope was nonsignificant $(.01, p=.68)$. This indicates that individuals low on proactive coping have significantly negative relationships between challenge appraisals across days, compared to individuals high on proactive coping. Hypothesis $2 \mathrm{~b}$ is therefore, supported.

The main and moderating effects of preventive coping on threat appraisal. The direct effects of preventive coping on threat appraisal were not significant, thus Hypothesis 3a was not supported (Table 3). However, the multi-level moderation effect of preventive coping on the relationship between days and threat appraisal was significant $\left(\gamma_{11}=-0.11, p<.05\right)$. Figure 2 depicts the interaction between days and threat appraisal for low and high levels of preventive coping. At low levels of preventive coping, the simple slope was significantly positive (.06, $p<$ 
$.05)$, while at high levels of preventive coping the simple slope approached significance (-0.05, $p$ $=.054)$. This indicates that the relationship between threat appraisals across days is only positive for those low in preventive coping, while individuals with higher preventive coping produce negative relationships. Hypothesis $3 b$ is therefore, supported.

\section{INSERT TABLE THREE ABOUT HERE}

\section{The main and moderating effects of proactive coping on hindrance appraisal. The}

direct effects of proactive coping on hindrance appraisal was not significant, offering no support for Hypothesis 4a (Table 4). However, the multi-level moderation effect of proactive coping on the relationship between days and hindrance appraisal was significant $\left(\gamma_{11}=-0.18, p<.001\right)$. Figure 3 depicts the interaction between days and hindrance appraisal for low and high levels of proactive coping. At low levels of proactive coping, the simple slope was significantly positive $(.06, p<.05)$, while at high levels of proactive coping, the simple slope was significantly negative $(-.12, p<.001)$. This indicates that the relationship between hindrance appraisals across days is only positive for those with low levels of proactive coping, while individuals with high proactive coping have reduced hindrance appraisals across days. Hypothesis $4 \mathrm{~b}$ is therefore, supported.

\section{The main and moderating effects of preventive coping on hindrance appraisal.}

Finally, the direct effects of preventive coping on hindrance appraisal was non-significant, thus Hypothesis 5a was not supported (Table 4). However, the multi-level moderation effect of preventive coping on the relationship between days and hindrance appraisal was significant $\left(\gamma_{11}=\right.$ $-.14, p<.01)$. Figure 4 depicts the interaction between days and hindrance appraisal for low and high levels of preventive coping. At low levels of preventive coping, the simple slope was not significant $(.05, p=.11)$, while at high levels of preventive coping, the simple slope was 
significantly negative $(-.10, p<.01)$. This indicates that individuals with high levels of preventive coping have reduced hindrance appraisals across days, compared to those with low preventive coping. Hypothesis $5 \mathrm{~b}$ is therefore, supported.

\section{INSERT TABLE FOUR AND FIGURES ONE TO FOUR ABOUT HERE}

\section{Discussion}

This study aimed to understand the dynamic nature of stress appraisals by measuring daily challenge, hindrance, and threat appraisals of a common future stressor, while also examining the main and moderating effects of proactive and preventive coping on daily stress appraisals as a common stressor approached. Results of the study were mixed as challenge appraisals tended to decrease over time, while the slopes between days and hindrance and threat appraisals were not significant (Hypotheses 1a, 1b, and 1c respectively). Hypothesis 2a was not supported as there was no main effect of proactive coping on challenge appraisal, however proactive coping moderated the relationship between days and challenge appraisals, supporting Hypotheses $2 \mathrm{~b}$. Hypothesis $3 \mathrm{a}$ was not supported as there was no association between preventive coping and threat appraisal, although preventive coping did moderate the relationship between days and threat appraisals, supporting Hypothesis $3 b$. Finally, the direct effects of proactive and preventive coping on daily hindrance appraisals were not significant (Hypotheses 4a and 5a, respectively) while both proactive and preventive coping moderated the relationship between days and hindrance appraisals, supporting Hypotheses $4 \mathrm{~b}$ and $5 \mathrm{~b}$, respectively.

\section{Theoretical Implications}

Daily changes in stress appraisals. Despite the transactional stress theory positing that stress appraisals are dynamic and can vary from day to day (Lazarus \& Folkman, 1984), the findings of the current research indicated daily appraisals are not so fluctuant. Unlike previous 
research findings of within-person changes of stress appraisals (Ohly \& Fritz, 2010), this research indicated that, on average, stress appraisals did not increase or decrease over time, with the only exception being that challenge appraisals did decrease slightly. A possible explanation of this result could be due to the context and timing of the future stressor (Skinner \& Brewer, 2002). As measurements of stress appraisals occurred in the days leading up to assignment submission, it could be that the stressor was already complete or near completion, resulting in stable daily appraisals. Skinner and Brewer (2002) found similar results when measuring challenge appraisals of a future stressful academic event across time, as state challenge appraisals decreased over a one-week period. Furthermore, appraisals could have been more fluctuant at an earlier stage due to the increased ambiguity associated with new stressors, particularly due to the lack of goal and objective formation (Rodell \& Judge, 2009). Despite finding no effects of time on hindrance and threat appraisals, the results indicated significant variation at the within-level suggesting appraisals do differ across measurement occasions, justifying the need to investigate daily changes of stress appraisals (Pindek et al., 2019).

The impact of proactive and preventive coping on daily stress appraisals. The results indicated a positive effect of proactive coping increasing daily challenge appraisals, however this was only marginally significant, offering partial support to Schwarzer and Taubert's (2002) conceptualisation of proactive coping. Contrary to what was hypothesised, there were no direct effects of preventive coping predicting daily threat appraisals while daily hindrance appraisals were not predicted by either proactive or preventive coping. A possible explanation could be that other coping mechanisms are more prominent in this context. As threat appraisals are known to increase anxiety (Tuckey et al., 2015), it could be that participants engaged in avoidance coping more so than preventive coping (Brough et al., 2005). In relation to the anger and frustration 
exhibited by hindrance appraisals, it could be that venting is the most appropriate form of coping (Searle \& Auton, 2015). As hindrance appraisals consist of obstruction of goals and learning outcomes, expressing these emotional outcomes as a way of coping could be more prevalent. As such, future research is recommended to include a wider variety of coping strategies to understand how different stress appraisals can initiate them and vice versa.

The moderating effects of future-oriented coping. Interestingly, the current research found that proactive coping moderated the relationship of challenge and hindrance appraisals across days, such that students high in proactive coping tended to have higher challenge appraisals and reduced hindrance appraisals across days. Similar trends occurred with individuals high in preventive coping, reporting reduced threat and hindrance appraisals across days. These findings support previous research indicating the moderating effect of future-oriented coping (Niessen et al., 2018; Stiglbauer \& Batinic, 2015). In addition, these findings are congruent with the common agreement amongst researchers that future-oriented coping can be considered as a personal resource (Searle \& Lee, 2015). In relation to the multi-level nature of the moderating effects of future-oriented coping, this research is consistent with previous findings (e.g., Espedido et al., 2019).

Individuals with high levels of proactive coping are more likely to accumulate resources more effectively and problem-solve more successfully. These students are more likely to attend relevant classes, which in turn, increases their challenge appraisals and reduces their hindrance appraisals of the task over time. Likewise, preventive copers effectively reduced the impacts of perceived impeding threats through increased planning and prevention of potential risks associated with their assessment. Future assessments of the stress and coping process are 
recommended to evaluate how coping processes impact the reappraisal process of specific challenge and hindrance job stressors, such as time pressure and ambiguity.

\section{Limitations and Future Research Directions}

The current research contained some research limitations which future studies should address. First, it is acknowledged that the inclusion of a student sample reduces the generalisability of the results, especially to occupational samples. However, we also recognise that future-oriented coping research is highly inclusive of student samples (e.g., Drummond \& Brough, 2016b; Gan et al., 2014; Sohl \& Moyer, 2009), all of which have been useful in the development of future-oriented coping research theory, models, and measures. Second, high correlations between proactive and preventive coping, and hindrance and threat appraisal, especially at the between level is acknowledged, indicating that these coping strategies and appraisals may differ more on the daily level as compared to individual differences at the between level. Previous research has also noted similar patterns when assessing these futureoriented coping strategies (e.g., Gan et al., 2007; Hu \& Gan, 2011; Sohl \& Moyer, 2009) and stress appraisals (e.g., Tuckey et al., 2015) concurrently. However, the current research did demonstrate differential effects of proactive coping on challenge appraisals and preventive coping on threat appraisals, as well as the relationship between days and hindrance appraisal being moderated by both proactive and preventive coping. It could be possible that those high on proactive coping would naturally be higher on preventive coping due to underlying traits such as proactive personality or future time perspective. Similarly, it could be that those people who appraise a stressor as a threat may more likely appraise it as a hindrance due to the goal obstructing and anxiety inducing nature of certain stressors. As such, future research is recommended to include measures of proactive personality or future time perspective, as well as 
simultaneous assessments of challenge, hindrance, and threat appraisals in order to assess how proactive and preventive coping and stress appraisals relate to various aspects of the psychosocial work environment.

The lower sample size at the between level can also limit generalisability and power, with many researchers unsure of how to calculate the required sample size (participants and measurement occasions) to detect adequate effects at both the between and withinperson levels (Bolger \& Laurenceau, 2013; Ohly et al., 2010). With the increase in complex, multi-level research designs, researchers should pay careful attention to ensure adequate samples at both levels of analysis, particularly when assessing the psychometric properties of measurement scales (Bolger \& Laurenceau, 2013).

Finally, more holistic approaches to assessing the transactional stress model would shed light on other aspects of the stress process. For example, other personal resources such as resilience and self-efficacy could help explain the reappraisal process over time (e.g., Crane et al., 2019). Furthermore, the role of job-related affect in assessments of job demands over time can be useful in understanding how emotions impact the relationships between various work characteristics and outcomes (e.g., Stiglbauer, 2018), as well as how proactive and preventive coping are associated with differing levels of anxiety to help distinguish between these coping mechanisms (Gan et al., 2007).

\section{Practical Implications}

The research findings indicate the positive effects of future-oriented coping through increased challenge appraisals and reduced negative appraisals. This suggests that proactive and preventive copers are more likely to accrue relevant resources to assist them in overcoming their stressors. Therefore, organisational stress and coping interventions can be usefully targeted at 
increasing employee proactivity in the workplace, particularly in relation to goal setting, planning for potential obstacles in the future, and seeking relevant information to reduce ambiguity (Strauss \& Parker, 2018). As this study focused on individual perceptions of future stressors, coaching also provides a valuable opportunity for employees to develop resilience to challenges and uncertainty. This approach can also assist employees to identify the specific challenging aspects of their work, while identifying and minimising perceived hindrances and threats.

\section{Conclusions}

In conclusion, this research has addressed recent calls to investigate the multi-level nature of the stress and coping process, particularly how future-oriented coping can influence daily stress appraisals of a common future stressor. Although the current research indicated appraisals may not differ much on a daily level, the moderating effects of proactive and preventive coping were observed. Proactive copers appear to have high challenge appraisals and reduced hindrance appraisals, while preventive copers tend to have reduced hindrance and threat appraisals over time. Organisational interventions could be developed to increase proactive coping in workplaces to create happier, healthier, and more productive employees. Future research should investigate how proactive personality and future time orientation are able to distinguish between proactive and preventive coping, as well as simultaneous assessments of challenge, hindrance, and threat appraisals, which will allow researchers to better understand the complexity of the occupational stress and coping process.

This article is protected by copyright. All rights reserved. 


\section{References}

Anderson, J. C., \& Gerbing, D. W. (1988). Structural equation modeling in practice: A review and recommended two-step approach. Psychological Bulletin, 103, 411-423.

Angelo, R. P., \& Chambel, M. J. (2014). The role of proactive coping in the Job DemandsResources Model: A cross-section study with firefighters. European Journal of Work and Organizational Psychology, 23(2), 203-216. doi:10.1080/1359432X.2012.728701

Aspinwall, L. G., \& Taylor, S. E. (1997). A stitch in time: Self-regulation and proactive coping. Psychological Bulletin, 121(3), 417-436. doi:10.1037/0033-2909.121.3.417

Biggs, A., Brough, P., \& Drummond, S. (2017). Lazarus and Folkman's psychological stress and coping theory. In C. Cooper \& J. C. Quick (Eds.), The Wiley handbook of stress and health: A guide to research and practice. London, UK: John Wiley and Sons.

Bolger, N., \& Laurenceau, J.-P. (2013). Intenstive longitudinal methods: An introduction to diary and experience sampling research. New York: Guilford Press.

Brough, P., Drummond, S., \& Biggs, A. (2018). Job support, coping, and control: Assessment of simultaneous impacts within the occupational stress process. Journal of Occupational Health Psychology, 23(2), 188-197. doi:10.1037/ocp0000074

Brough, P., O'Driscoll, M., \& Kalliath, T. (2005). Evaluating the criterion validity of the Cybernetic Coping Scale: Cross-lagged predictions of psychological strain, job and family satisfaction. Work \& Stress, 19(3), 276-292. doi:10.1080/02678370500287507

Cavanaugh, M. A., Boswell, W. R., Roehling, M. V., \& Boudreau, J. W. (2000). An empirical examination of self-reported work stress among U.S. managers. Journal of Applied Psychology, 85(1), 65-74. doi:10.1037/0021-9010.85.1.65

This article is protected by copyright. All rights reserved. 
Crane, M. F., Searle, B. J., Kangas, M., \& Nwiran, Y. (2019). How resilience is strengthened by exposure to stressors: the systematic self-reflection model of resilience strengthening. Anxiety Stress Coping, 32(1), 1-17. doi:10.1080/10615806.2018.1506640

Crawford, E. R., Lepine, J. A., \& Rich, B. L. (2010). Linking job demands and resources to employee engagement and burnout: a theoretical extension and meta-analytic test. Journal of Applied Psychology, 95(5), 834-848. doi:10.1037/a0019364

Drummond, S., \& Brough, P. (2016a). Future-oriented coping and personality. In A.-S. Antoniou, C. L. Cooper, \& R. J. Burke (Eds.), Coping, personality and the workplace: Responding to psychological crisis and critical events. London, UK: Routledge

Drummond, S., \& Brough, P. (2016b). Proactive coping and preventive coping: Evidence for two distinct constructs? Personality and Individual Differences, 92, 123-127. doi:10.1016/j.paid.2015.12.029

Espedido, A., \& Searle, B. J. (2018). Goal difficulty and creative performance: The mediating role of stress appraisal. Human Performance, 31(3), 179-196. doi:10.1080/08959285.2018.1499024

Espedido, A., Searle, B. J., \& Griffin, B. (2019). Peers, proactivity, and problem-solving: A multilevel study of team impacts on stress appraisals of problem-solving demands. Work \& Stress. doi:10.1080/02678373.2019.1579767

Feldman, P. J., Cohen, S., Hamrick, N., \& Lepore, S. J. (2004). Psychological stress, appraisal, emotion and cardiovascular response in a public speaking task. Psychology \& Health, 19(3), 353-368. doi:10.1080/0887044042000193497

This article is protected by copyright. All rights reserved. 
Gan, Y. Q., Yang, M. S., Zhou, Y., \& Zhang, Y. L. (2007). The two-factor structure of futureoriented coping and its mediating role in student engagement. Personality and Individual Differences, 43(4), 851-863. doi:10.1016/j.paid.2007.02.009

Gan, Y. Q., Zheng, W., \& Wen, Y. (2014). The Sequential Model of Future-Oriented Coping and Adjustment to University Life: The Role of Attitudes as Further Evidence. Psychological Record, 64(1), 13-20. doi:10.1007/s40732-014-0024-0

Geldhof, G. J., Preacher, K. J., \& Zyphyr, M. J. (2014). Reliability estimation in a multilevel confirmatory factor analysis framework. Psychological Methods, 19(1), 72-91. doi:10.1037/a0032138

Greenglass, E. R., \& Fiksenbaum, L. (2009). Proactive Coping, Positive Affect, and Well-Being Testing for Mediation Using Path Analysis. European Psychologist, 14(1), 29-39. doi:10.1027/1016-9040.14.1.29

Greenglass, E. R., Schwarzer, R., \& Taubert, S. (1999). The Proactive Coping Inventory (PCI): A multidimensional research instrument. Retrieved from http://userpage.fuberlin.de/ health/greenpci.htm

Higgins, E. T., Friedman, R. S., Harlow, R. E., Idson, L. C., Ayduk, O. N., \& Tayler, A. (2001). Achievement orientations from subjective histories of success: Promotion pride versus prevention pride. European Journal of Social Psychology, 31(1), 3-23. doi:10.1002/ejsp.27

Hu, Y. Q., \& Gan, Y. Q. (2011). Future-Oriented Coping and Job Hunting among College Students. Psychological Record, 61(2), 253-268. doi:Doi 10.1007/Bf03395759

Lazarus, R. S. (1991). Progress on a cognitive-motivational-relational theory of emotion. Am Psychol, 46(8), 819-834. doi:10.1037/0003-066X.46.8.819 
Lazarus, R. S., \& Folkman, S. (1984). Stress, appraisal, and coping. US: Springer Publishing Company, Incorporated.

Muthén, L. K., \& Muthén, B. O. (1998-2017). Mplus User's Guide(8th ed.).

Niessen, C., Müller, T., Hommelhoff, S., \& Westman, M. (2018). The impact of preventive coping on business travelers' work and private life. Journal of Organizational Behavior, 39(1), 113-127. doi:10.1002/job.2215

O'Brien, K. E., \& Beehr, T. A. (2019). So far, so good: Up to now, the challenge-hindrance framework describes a practical and accurate distinction. Journal of Organizational Behavior, 40, 962-972. doi:10.1002/job.2405

Ohly, S., \& Fritz, C. (2010). Work characteristics, challenge appraisal, creativity, and proactive behavior: A multi-level study. Journal of Organizational Behavior, 31(4), 543-565. doi:10.1002/job.633

Ohly, S., Sonnentag, S., Niessen, C., \& Zapf, D. (2010). Diary studies in organizational research. Journal of Personnel Psychology, 9(2), 79-93. doi:10.1027/1866-5888/a000009

Pindek, S., Arvan, M. L., \& Spector, P. E. (2019). The stressor-strain relationship in diary studies: A meta-analysis of the within and between levels. Work \& Stress, 33(1), 1-21. doi:10.1080/02678373.2018.1445672

Preacher, K. J., Curran, P. J., \& Bauer, D. J. (2006). Computational tools for probing interactions in multiple linear regression, multilevel modeling, and latent curve analysis. Journal of Educational and Behavioral Statistics, 31(4), 437-448. doi:10.3102/10769986031004437

This article is protected by copyright. All rights reserved. 
Rodell, J. B., \& Judge, T. A. (2009). Can "good" stressors spark "bad" behaviors? The mediating role of emotions in links of challenge and hindrance stressors with citizenship and counterproductive behaviors. Journal of Applied Psychology, 94(6), 1438-1451. doi:10.1037/a0016752

Schwarzer, R. (2000). Manage stress at work through preventive and proactive coping. In E. A. Locke (Ed.), The Blackwell handbook of principles of organizational behavior (pp. 342355). Oxford: Blackwell Publishers Ltd.

Schwarzer, R., \& Taubert, S. (2002). Tenacious goal pursuits and striving toward personal growth: Proactive coping In E. Frydenberg (Ed.), Beyond coping: Meeting goals, visions and challenges (pp. 19-35). London, UK: Oxford University Press.

Searle, B. J., \& Auton, J. C. (2015). The merits of measuring challenge and hindrance appraisals. Anxiety, Stress \& Coping, 28(2), 121-143. doi:10.1080/10615806.2014.931378

Searle, B. J., \& Lee, L. (2015). Proactive Coping as a Personal Resource in the Expanded Job Demands-Resources Model. International Journal of Stress Management, 22(1), 46-69. doi:10.1037/a0038439

Skinner, N., \& Brewer, N. (2002). The dynamics of threat and challenge appraisals prior to stressful achievement events. Journal of Personality and Social Psychology, 83(3), 678692. doi:10.1037//0022-3514.83.3.678

Sohl, S. J., \& Moyer, A. (2009). Refining the Conceptualization of an Important Future-Oriented Self-Regulatory Behavior: Proactive Coping. Personality and Individual Differences, 47(2), 139-144. doi:10.1016/j.paid.2009.02.013

This article is protected by copyright. All rights reserved. 
Stiglbauer, B. (2018). Differential challenge and hindrance stressor relations with job-related core affect. International Journal of Stress Management, 25(S1), 62-80. doi:10.1037/str0000076

Stiglbauer, B., \& Batinic, B. (2015). Proactive coping with job insecurity: Is it always beneficial to well-being? Work \& Stress, 29(3), 264-285. doi:10.1080/02678373.2015.1074956

Strauss, K., \& Parker, S. K. (2018). Intervening to enhance proactivity in organizations: Improving the present or changing the future. Journal of Management, 44(3), 1250-1278. doi:10.1177/0149206315602531

Tuckey, M. R., Searle, B. J., Boyd, C. M., Winefield, A. H., \& Winefield, H. R. (2015). Hindrances are not threats: advancing the multidimensionality of work stress. Journal of Occupational Health Psychology, 20(2), 131-147. doi:10.1037/a0038280

Webster, J. R., Beehr, T. A., \& Love, K. (2011). Extending the challenge-hindrance model of occupational stress: The role of appraisal. Journal of Vocational Behavior, 79(2), 505516. doi:10.1016/j.jvb.2011.02.001

This article is protected by copyright. All rights reserved. 
Table 1

Descriptive Statistics and Correlations between the Research Variables.

\begin{tabular}{lccccccccc}
\hline & $M$ & $S D_{b}$ & $I C C$ & 1 & 2 & 3 & 4 & 5 & 6 \\
\hline$S D_{\mathrm{w}}$ & & & - & 0.31 & 0.27 & 0.40 & 0.33 & 0.42 & - \\
1. Challenge Appraisal & 3.49 & 0.68 & .83 & - & $-.39 * * *$ & $-.31 * * *$ & $.18^{* *}$ & .13 & $-.25^{* *}$ \\
2. Hindrance Appraisal & 2.49 & 0.54 & .80 & $-.61 * * *$ & - & $.48^{* * *}$ & -.02 & .08 & -.05 \\
3. Threat Appraisal & 2.68 & 0.81 & .80 & $-.62 * * *$ & $.74 * * *$ & - & $-.27 * *$ & -.11 & .03 \\
4. Proactive Coping & 2.36 & 0.67 & .67 & $.37-* *$ & $-.37 * * *$ & $-.50^{* * *}$ & - & $.70^{* * *}$ & .07 \\
5. Preventive Coping & 2.33 & 0.52 & .56 & .19 & $.26 *$ & -.15 & $.79 * * *$ & - & .08 \\
6. Days & - & - & - & - & - & - & - & - & - \\
\hline
\end{tabular}

Note. Between-person correlations are shown below the diagonal $(N=89)$, within-person correlations are shown above the diagonal $(N=396)$; ICC $=$ intraclass correlation, $* p<.05$, $* * p<.01, * * * p<.001$.

This article is protected by copyright. All rights reserved. 


\section{Table 2}

Main effects models examining the relationship between time and stress appraisals.

\begin{tabular}{|c|c|c|c|c|c|c|c|c|c|}
\hline \multirow[b]{2}{*}{ Model } & \multicolumn{3}{|c|}{ Challenge Appraisal } & \multicolumn{3}{|c|}{ Hindrance Appraisal } & \multicolumn{3}{|c|}{ Threat Appraisal } \\
\hline & Coefficients & $S E$ & $95 \% \mathrm{CI}$ & Coefficients & $S E$ & $95 \% \mathrm{CI}$ & Coefficients & $S E$ & $95 \% \mathrm{CI}$ \\
\hline \multicolumn{10}{|l|}{ Random Intercept $\left(\beta_{0}\right)$} \\
\hline Mean $\left(\gamma_{00}\right)$ & $3.64 * * *$ & 0.07 & {$[3.51,3.77]$} & $2.55 * * *$ & 0.08 & {$[2.40,2.70]$} & $2.67 * * *$ & 0.10 & {$[2.48,2.85]$} \\
\hline Residual Variance $\left(\sigma_{\mathrm{e} 0}^{2}\right)$ & $0.10 * * *$ & 0.02 & {$[0.07,0.13]$} & $0.16^{* * *}$ & 0.03 & {$[0.11,0.21]$} & $0.19 * * *$ & 0.02 & {$[0.14,0.23]$} \\
\hline \multicolumn{10}{|l|}{ Random Slope $\left(\beta_{1}\right)$} \\
\hline Mean $\left(\gamma_{10}\right)$ & $-0.05 * * *$ & 0.02 & {$[-0.08,-0.02]$} & -0.02 & 0.02 & {$[-0.06,0.02]$} & $0.00^{\mathrm{a}}$ & 0.02 & {$[-0.03,0.04]$} \\
\hline Variance $\left(\tau_{0}\right)$ & $0.01 * * *$ & $0.00^{\mathrm{a}}$ & {$[0.01,0.02]$} & $0.01 *$ & 0.01 & {$\left[0.00^{\mathrm{b}}, 0.02\right]$} & $0.01 *$ & 0.01 & {$\left[0.00^{\mathrm{b}}, 0.02\right]$} \\
\hline
\end{tabular}

Note. $N=396, \mathrm{CI}=$ confidence interval, ${ }^{\mathrm{a}}=0.004,{ }^{\mathrm{b}}=0.001$, Level 1 equation: appraisal (challenge, hindrance, threat) $=\beta_{0}+\beta_{1}(\mathrm{days})+e$.

Level 2 equations: $\beta_{0}=\gamma_{00}+\mu_{0}$, and $\beta_{1}=\gamma_{10}+\mu_{1} * p<.05$, *** $p<.001$. 


\section{Table 3}

Multi-level Analysis examining the cross-level moderation of proactive coping on daily challenge appraisals and preventive coping on daily threat appraisals.

\begin{tabular}{|c|c|c|c|c|c|c|c|}
\hline \multirow[b]{2}{*}{ Model } & \multicolumn{3}{|c|}{ Challenge Appraisal } & \multirow[b]{2}{*}{ Model } & \multicolumn{3}{|c|}{ Threat Appraisal } \\
\hline & Coefficients & $S E$ & $95 \% \mathrm{CI}$ & & Coefficients & $S E$ & $95 \% \mathrm{CI}$ \\
\hline Random Intercept $\left(\beta_{0}\right)$ & & & & Random Intercept $\left(\beta_{0}\right)$ & & & \\
\hline Intercept $\left(\gamma_{00}\right)$ & $3.00 * * *$ & 0.38 & {$[2.26,3.73]$} & Intercept $\left(\gamma_{00}\right)$ & $2.57 * * *$ & 0.55 & {$[1.50,3.64]$} \\
\hline Proactive Coping $\left(\gamma_{01}\right)$ & 0.27 & 0.16 & {$[-0.04,0.58]$} & Preventive Coping $\left(\gamma_{01}\right)$ & 0.04 & 0.23 & {$[-.41,0.50]$} \\
\hline Residual Variance $\left(\sigma_{\mathrm{e} 0}^{2}\right)$ & $0.26 *$ & 0.06 & {$[0.14,0.38]$} & Residual Variance $\left(\sigma_{\mathrm{e} 0}^{2}\right)$ & $0.57 * * *$ & 0.13 & {$[0.33,0.82]$} \\
\hline Random Slope $\left(\beta_{1}\right)$ & & & & Random Slope $\left(\beta_{1}\right)$ & & & \\
\hline Intercept $\left(\gamma_{10}\right)$ & $-0.26 * *$ & 0.09 & {$[-0.44,-0.08]$} & Intercept $\left(\gamma_{10}\right)$ & $0.26^{*}$ & 0.11 & {$[0.05,0.47]$} \\
\hline $\begin{array}{l}\text { Proactive Coping }- \text { cross } \\
\text { level moderation effect }\left(\gamma_{11}\right)\end{array}$ & $0.09 *$ & 0.04 & {$[0.02,0.17]$} & $\begin{array}{l}\text { Preventive Coping - cross } \\
\text { level moderation effect }\left(\gamma_{11}\right)\end{array}$ & $-0.11 *$ & 0.05 & {$[-0.20,-0.02]$} \\
\hline Residual Variance $\left(\sigma_{\mathrm{e} 0}^{2}\right)$ & $0.01 * *$ & $0.00^{\mathrm{a}}$ & {$\left[0.00^{\mathrm{a}}, 0.02\right]$} & Residual Variance $\left(\sigma_{\mathrm{e} 0}^{2}\right)$ & 0.01 & 0.01 & {$\left[-0.00^{\mathrm{b}}, 0.02\right]$} \\
\hline
\end{tabular}

Note. $N=396, \mathrm{CI}=$ confidence interval, ${ }^{\mathrm{a}}=0.004,{ }^{\mathrm{b}}=-0.001$, Level 1 equation: appraisal (challenge, hindrance, threat) $=\beta_{0}+\beta_{1}(\mathrm{days})+e$. Level 2 equations: $\beta_{0}=\gamma_{00}+\gamma_{01}$ (proactive/preventive coping) $+\mu_{0}$, and $\beta_{1}=\gamma_{10}+\gamma_{11}$ (proactive/preventive coping) $+\mu_{1}, * p<.05$, ** $p<.01$, $* * * p<.001$. 


\section{Table 4}

Multi-level Analysis examining the cross-level moderation of proactive and preventive coping on daily hindrance appraisals.

\begin{tabular}{|c|c|c|c|c|c|c|c|}
\hline \multirow[b]{2}{*}{ Model } & \multicolumn{3}{|c|}{ Hindrance Appraisal } & \multirow[b]{2}{*}{ Model } & \multicolumn{3}{|c|}{ Hindrance Appraisal } \\
\hline & Coefficients & $S E$ & $95 \% \mathrm{CI}$ & & Coefficients & $S E$ & $95 \% \mathrm{CI}$ \\
\hline Random Intercept $\left(\beta_{0}\right)$ & & & & Random Intercept $\left(\beta_{0}\right)$ & & & \\
\hline Intercept $\left(\gamma_{00}\right)$ & $2.46^{* * *}$ & 0.44 & {$[1.61,3.31]$} & Intercept $\left(\gamma_{00}\right)$ & $2.34 * * *$ & 0.44 & {$[1.48,3.20]$} \\
\hline Proactive Coping $\left(\gamma_{01}\right)$ & 0.04 & 0.18 & {$[-0.31,0]$.} & Preventive Coping $\left(\gamma_{01}\right)$ & 0.09 & 0.19 & {$[-0.27,0.45]$} \\
\hline Residual Variance $\left(\sigma_{\mathrm{e} 0}^{2}\right)$ & $0.32 * * *$ & 0.08 & {$[0.16,0.48]$} & Residual Variance $\left(\sigma_{\mathrm{e} 0}^{2}\right)$ & $0.32 * *$ & 0.08 & {$[0.16,0.48]$} \\
\hline Random Slope $\left(\beta_{1}\right)$ & & & & Random Slope $\left(\beta_{1}\right)$ & & & \\
\hline Intercept $\left(\gamma_{10}\right)$ & $0.39 * * *$ & 0.09 & {$[0.21,0.57]$} & Intercept $\left(\gamma_{10}\right)$ & $0.30 * *$ & 0.10 & {$[0.11,0.50]$} \\
\hline $\begin{array}{l}\text { Proactive Coping - cross } \\
\text { level moderation effect }\left(\gamma_{11}\right)\end{array}$ & $-0.18 * * *$ & 0.04 & {$[-0.25,-0.10]$} & $\begin{array}{l}\text { Preventive Coping }- \text { cross } \\
\text { level moderation effect }\left(\gamma_{11}\right)\end{array}$ & $-0.14 * *$ & 0.04 & {$[-0.22,-0.06]$} \\
\hline Residual Variance $\left(\sigma_{\mathrm{e} 0}^{2}\right)$ & $0.00^{\mathrm{a}}$ & 0.01 & {$[-0.01,0.01]$} & Residual Variance $\left(\sigma_{\mathrm{e} 0}^{2}\right)$ & 0.01 & 0.01 & {$\left[-0.00^{\mathrm{b}}, 0.02\right]$} \\
\hline
\end{tabular}

Note. $N=396, \mathrm{CI}=$ confidence interval, ${ }^{\mathrm{a}}=0.004,{ }^{\mathrm{b}}=-0.002$, Level 1 equation: appraisal (challenge, hindrance, threat $)=\beta_{0}+\beta_{1}($ days $)+e$.

Level 2 equations: $\beta_{0}=\gamma_{00}+\gamma_{01}$ (proactive/preventive coping) $+\mu_{0}$, and $\beta_{1}=\gamma_{10}+\gamma_{11}$ (proactive/preventive coping) $+\mu_{1}$, ** $p<.01$, *** $p<$ .001 . 


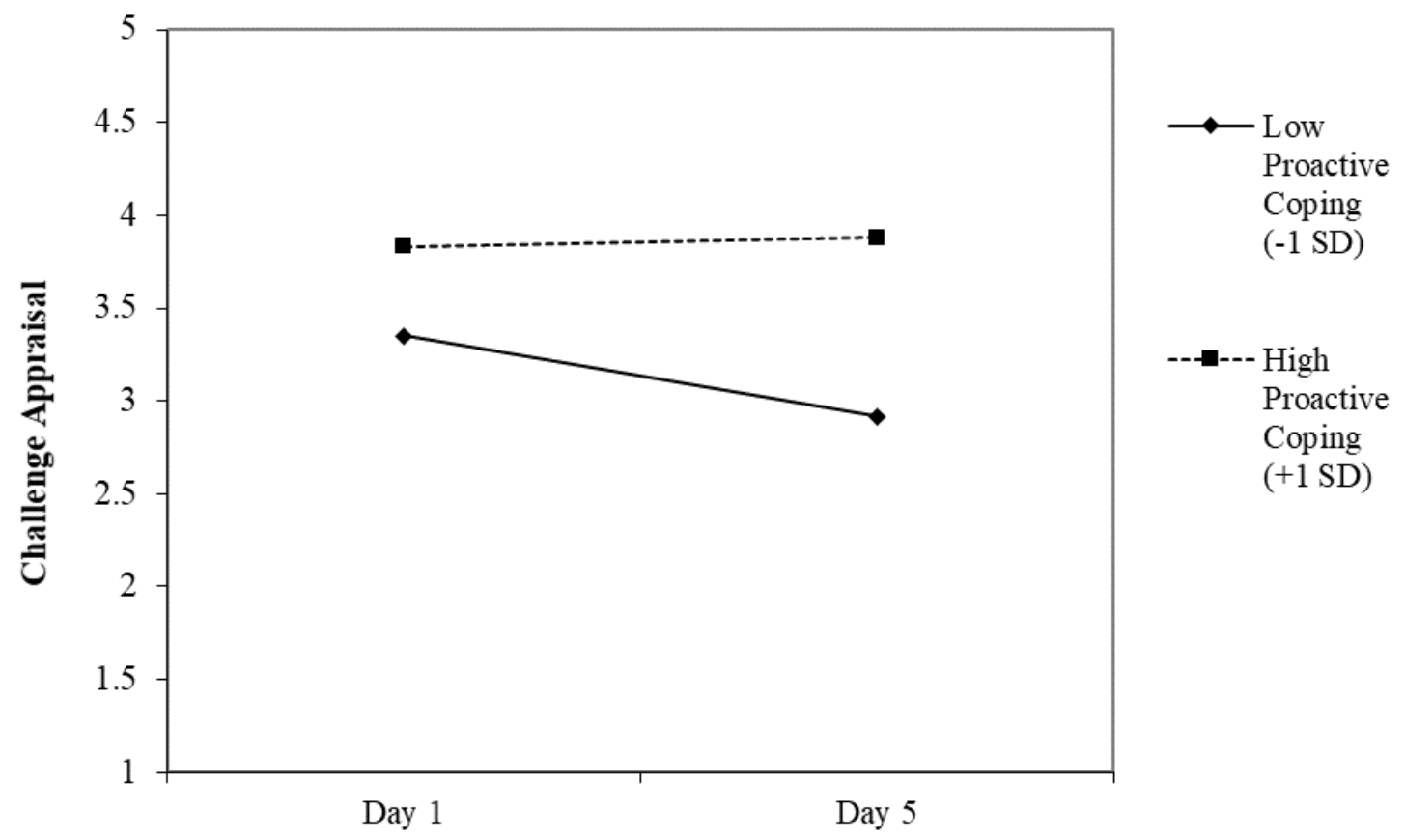

This article is protected by copyright. All rights reserved. 


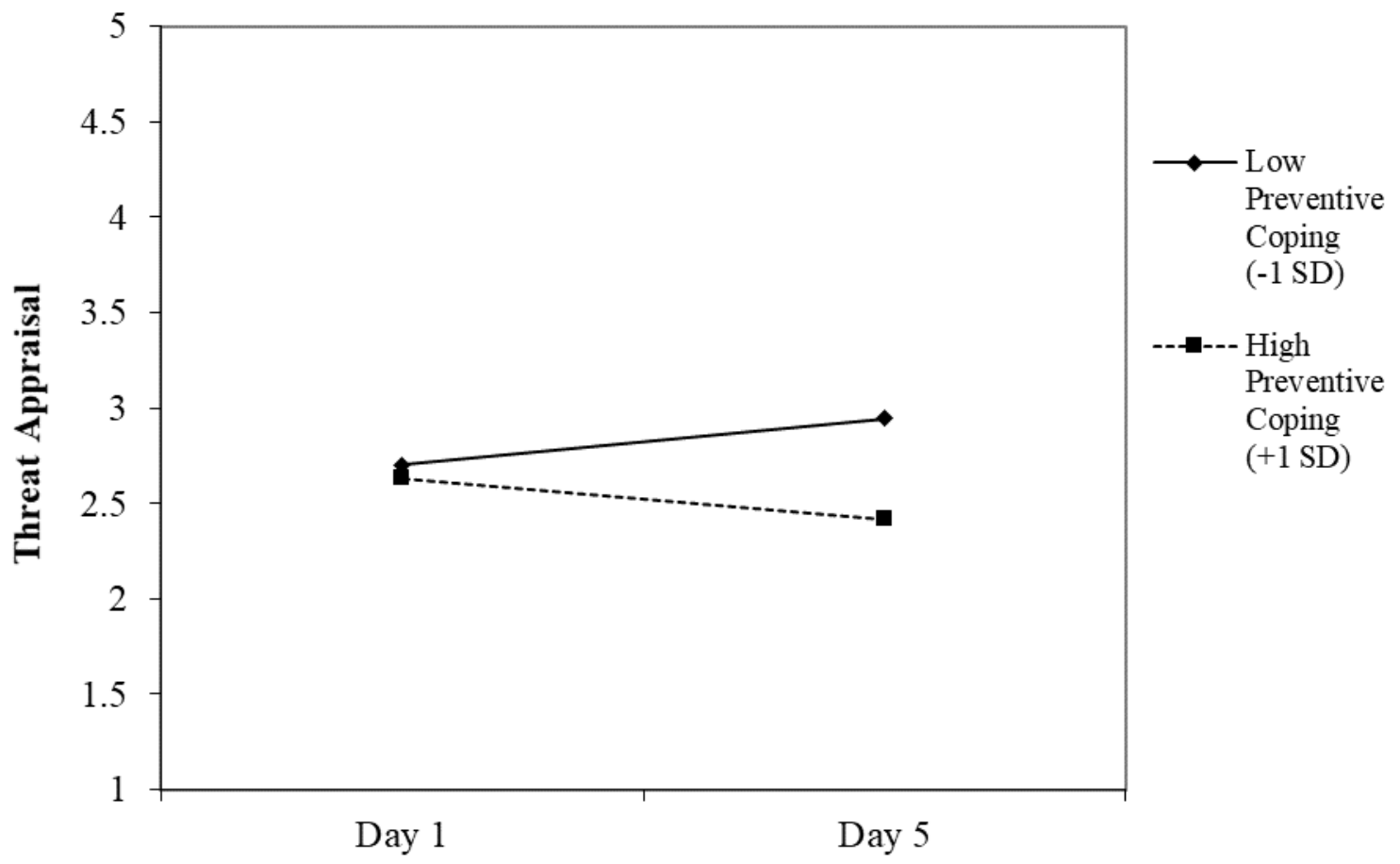

This article is protected by copyright. All rights reserved. 


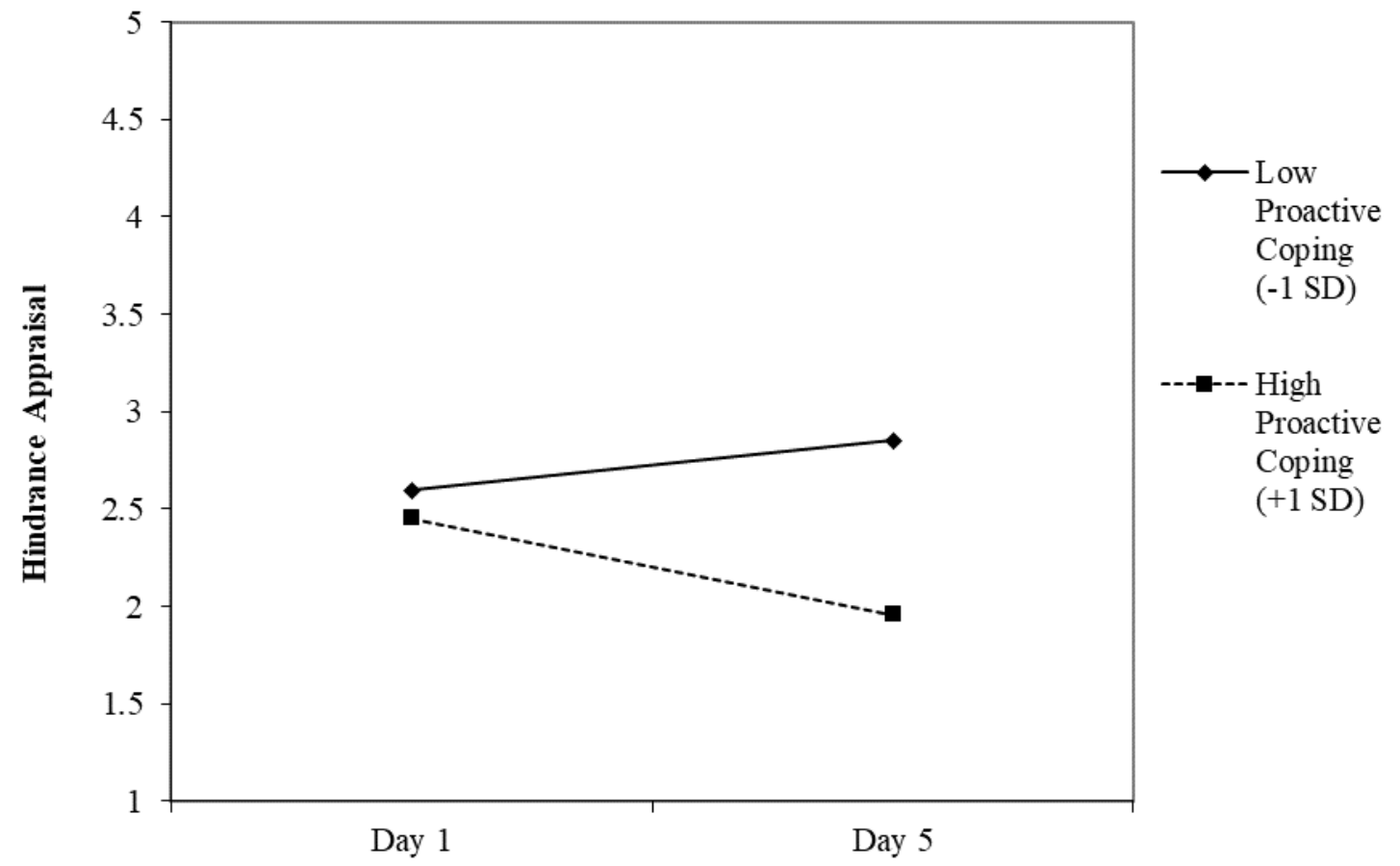

This article is protected by copyright. All rights reserved. 


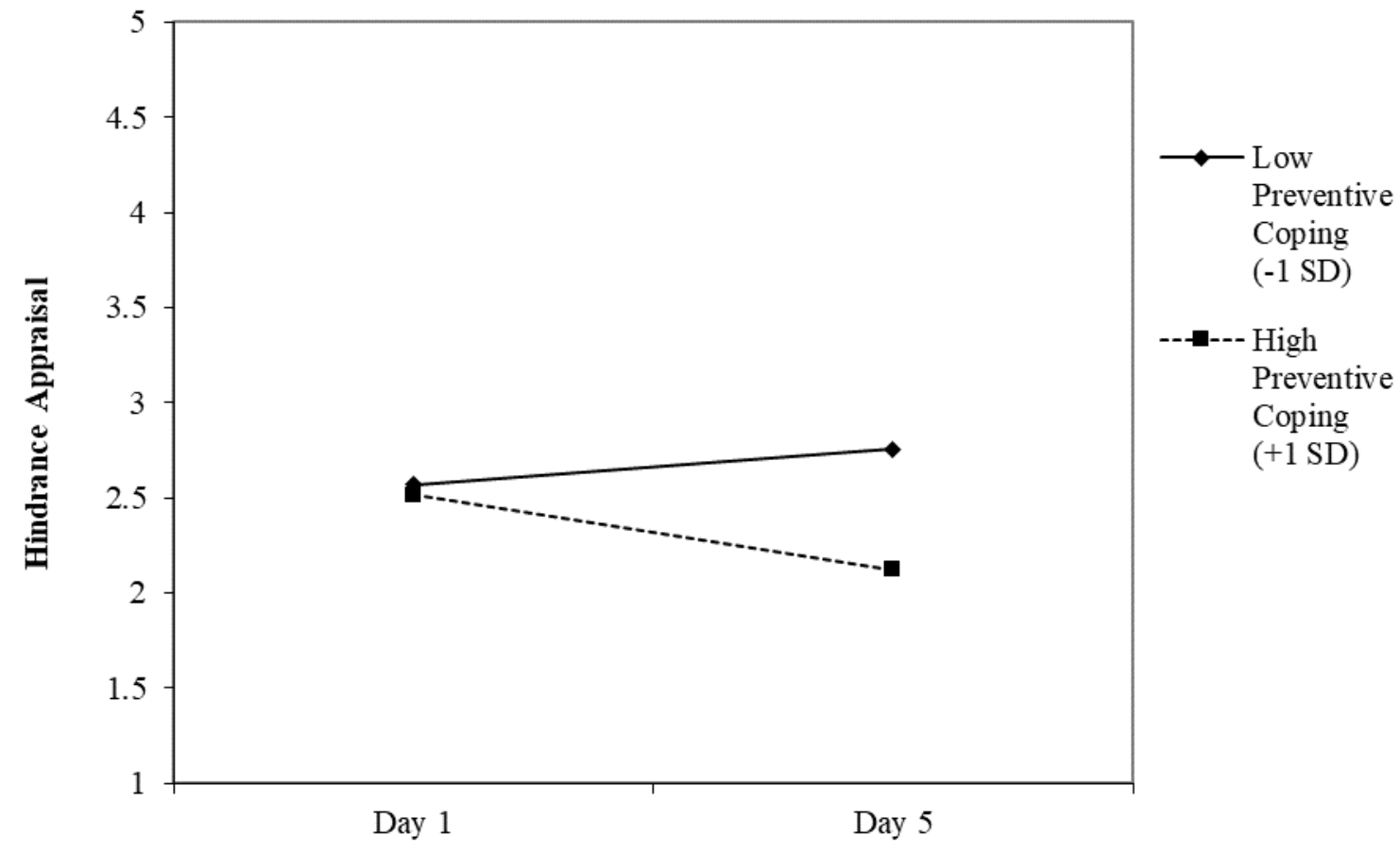

This article is protected by copyright. All rights reserved. 